\title{
Complications of fluid overload during hysteroscopic surgery
}

\author{
Christopher Ryan Hoffman, Michele Van Hal, Rayhan Tariq, and \\ Shelley George
}

Department of Anesthesiology and Perioperative Medicine, Drexel University College of Medicine, Hahnemann University Hospital, Philadelphia, PA, USA

Hysteroscopy is a tool utilized in many diagnostic and therapeutic procedures to remain minimally invasive and reduce complication rates when compared to operative procedures [1]. The incidence of all complications is less than $5 \%$. Fluid overload is one potential complication, occurring in $0.2 \%-6.0 \%$ of cases $[1,2]$. Fluid distension to optimize visualization relies upon electrolyte-free, hypotonic solutions when surgical equipment includes monopolar cutting tools. Bipolar electrical systems, which enable the use of isotonic distension fluids, may still lead to complications from fluid overload [3]. Reports on this complication in gynecologic surgery is scarce in the literature. However, this does not negate the necessity for attention to this possible adverse event especially considering the ubiquity of hysteroscopy [4]. We describe a patient who underwent a hysteroscopy procedure with hemodynamic and pulmonary complications secondary to fluid overload.

A 42-year-old woman underwent a hysteroscopic resection of uterine fibroids under general anesthesia with informed consent. The uterus measured $9.1 \times 4.2 \times 6.6 \mathrm{~cm}$ with multiple fibroids, the largest being $3.4 \times 2.4 \times 2.1 \mathrm{~cm}$ and $2.1 \times 2.1 \times 1.8$

Corresponding author: Christopher Ryan Hoffman, D.O.

Department of Anesthesiology and Perioperative Medicine, Drexel University College of Medicine, Hahnemann University Hospital, 245 N. 15th Street, Suite 7502, MS 310, Philadelphia, PA 19102, USA

Tel: +1-215-762-8936, Fax: +1-215-762-8656

Email:crh33@drexel.edu

ORCID: https://orcid.org/0000-0001-8387-1060

This work has previously been presented in part at ANESTHESIOLOGY 2018 Annual Meeting of The American Society of Anesthesiologists (ASA), October 2018, Moscone Center, San Francisco, CA, USA.

Received: January 1, 2019.

Revised: January 6, 2019.

Accepted: January 28, 2019.

Korean J Anesthesiol 2019 August 72(4): 387-388

https://doi.org/10.4097/kja.d.18.00374 $\mathrm{cm}$. Anesthesia was induced with propofol and fentanyl and maintained with sevoflurane/oxygen/air mixture via a laryngeal mask device. She was hemodynamically stable with adequate ventilation and oxygenation. The procedure progressed with the patient in the Trendelenberg position at the surgeon's request. Approximately two and half hours into the case, the patient's tidal volumes decreased and peak airway pressures increased with subsequent desaturation. It was difficult to bag ventilate the patient and she became hemodynamically unstable. The laryngeal mask airway was replaced by an endotracheal tube and subsequent mechanical ventilation improved oxygen saturation and stabilized hemodynamics. Chest auscultation revealed diffuse crackles. A final total of one thousand and three hundred cubic centimeters of crystalloid was administered intravenously over the two and a half hour case. Two thousand and ten cubic centimeters of $0.9 \%$ normal saline irrigation fluid was measured. A 16 French Foley catheter placed by the surgical team yielded 700 $\mathrm{cc}$ of voided urine immediately. The procedure ended and the patient was taken to the surgical intensive care unit intubated. A postoperative chest X-ray image showed bilateral patchy opacification. Ventilation with high positive end expiratory pressure was initiated and furosemide was administered. Arterial blood gas yielded hypercapnia $\left(\mathrm{pCO}_{2} 49.5 \mathrm{mmHg}\right)$ and hypoxemia $\left(\mathrm{pO}_{2} 327 \mathrm{mmHg}\right.$ on $\left.100 \% \mathrm{FiO}_{2}\right)$. There were no significant metabolic derangements postoperatively (e.g., serum sodium, potassium, and glucose). Following treatment, the patient was extubated five hours later. Clinical and radiographic evaluation showed no abnormalities. The patient was discharged uneventfully the next day.

Transurethral, hysteroscopic, and other percutaneous procedures utilize large volumes of irrigating and/or distension solutions. Complications of hysteroscopy include uterine perforation, hemorrhage, and gas embolism [1]. Fluid overload complications such as subsequent hyponatremia, hypo-osmolality, hypothermia, pulmonary edema, cerebral edema, or heart

(c) This is an open-access article distributed under the terms of the Creative Commons Attribution Non-Commercial License (http://creativecommons.org/ licenses/by-nc/4.0/), which permits unrestricted non-commercial use, distribution, and reproduction in any medium, provided the original work is properly cited. 
failure, can be fatal. Procedure duration and patient positioning may also affect the extent to which venous sinuses accumulate distension medium. The type of distending medium used contributes to pathophysiology [5]. Specific additives can have adverse effects. Absorbed glycine may induce cardiac and renal toxicity. Glycine can be metabolized in the liver to ammonia and may lead to visual impairment. High ammonia levels may result in neurologic disturbance. It is important for anesthesia practitioners to be aware of and recognize the potential symptomatology during hysteroscopy. In the present case, the patient demonstrated fluid overload likely secondary to rapid absorption of fluids. Communication with the surgical team regarding the possible concerns for fluid overload and a meticulous attention to patient hemodynamic patterns via noninvasive or invasive monitors is warranted.

\section{Conflicts of Interest}

No potential conflict of interest relevant to this article was reported.

\section{Author Contributions}

Christopher Ryan Hoffman (Conceptualization; Supervision; Writing - original draft; Writing - review \& editing)

Michele Van Hal (Writing - original draft)

Rayhan Tariq (Writing - original draft)

Shelley George (Project administration)

\section{ORCID}

Christopher Ryan Hoffman, https://orcid.org/0000-0001-83871060

Michele Van Hal, https://orcid.org/0000-0003-3156-0580

Rayhan Tariq, https://orcid.org/0000-0002-7648-9741

Shelley George, https://orcid.org/0000-0001-7005-4213

\section{References}

1. Jansen FW, Vredevoogd CB, van Ulzen K, Hermans J, Trimbos JB, Trimbos-Kemper TC. Complications of hysteroscopy: a prospective, multicenter study. Obstet Gynecol 2000; 96: 266-70.

2. Nicoloso E, Carvello L, d'Ercole C, Boubli L, Blanc C. Les complications de hystéroscopie: Enquete nationale prospective a propos de 2757 hystéroscopies. Rev Fr Gynecol Obstet 1997; 92: 91-8.

3. Schäfer M, Von Ungern-Sternberg BS, Wight E, Schneider MC. Isotonic fluid absorption during hysteroscopy resulting in severe hyperchloremic acidosis. Anesthesiology 2005; 103: 203-4.

4. Varol N, Maher P, Vancaillie T, Cooper M, Carter J, Kowk A, et al. A literature review and update on the prevention and management of fluid overload in endometrial resection and hysteroscopic surgery. Gynaecol Endosc 2002; 11: 19-26.

5. Paschopoulos M, Polyzos NP, Lavasidis LG, Vrekoussis T, Dalkalitsis N, Paraskevaidis E. Safety issues of hysteroscopic surgery. Ann N Y Acad Sci 2006; 1092: 229-34. 